\title{
Investigation on mm-wave sintering of metal powder compacts using in-situ dilatometry and electrical resistivity measurements
}

\author{
M. Mahmoud ${ }^{1,2}, \underline{\text { G. Link }}{ }^{1}$, J. Jelonnek ${ }^{1}$ and M. Thumm ${ }^{1}$ \\ ${ }^{1}$ Karlsruhe Institute of Technology, IHM, Karlsruhe, Germany, guido.link@kit.edu \\ ${ }^{2}$ King Fahd University of Petroleum and Minerals (KFUPM), KSA \& City for Scientific Research and Technological Applications \\ (SRTA City), Egypt
}

\section{Introduction}

Sintering of metal powders is a well-established industrial process for specific applications, which allow a cheap series production of metal parts even with complex shape. The residual porosity, always present in sintered power compacts, limits their mechanical strength. On the other hand, for several products such porosity is needed. Products of that kind are for example: metal filters showing a porosity of about $50 \%$, or self-lubricating plain bearings with a value between $5 \%$ and $30 \%$, depending on the technological working conditions. In the case of self-lubricating plain bearings made of sintered iron or sintered brass, the open pores are filled with lubricants. Pore-free sinter metals are obtained by hot pressing or impregnation with a low-melting metal

The use of microwave technology for metal powder sintering had been reported by many researchers, demonstrating improvements in the materials properties and/or in the overall process. Although microwave are not able to penetrate into bull metals, significant penetration depth in metal power compacts has been reported by theoretical as well as experimental investigations $[1,2]$.

Here, the progress of microwave sintering of metal power compacts with focus on copper powders was investigated by systematic variation of process parameters. Those investigations were supported by both in-situ electrical resistivity and dilatometry measurements that give important information about the sintering progress and microstructural changes.

\section{Experimental}

In this study microwave sintering experiments on copper powder compacts were done at $30 \mathrm{GHz}$ in a compact gyrotron device. Changes in sample length due to thermal expansion or sintering were measured by use of a commercial dilatometer from Linseis $\mathrm{GmbH}$, Germany. This has been adapted to the mm-wave applicator and was combined with in-situ electrical resistivity measurements using the four-wire method [3]. The sintering temperatures were limited to $1000^{\circ} \mathrm{C}$, ensuring sufficient temperature difference to the melting point of copper. The sintering process was performed at inert gas atmosphere such as nitrogen $\left(\mathrm{N}_{2}\right)$ and argon (Ar) as well as in a forming gas environment with $8 \%$ hydrogen $\left(\mathrm{N}_{2} / \mathrm{H}_{2}\right)$.

For sample preparation commercial gas atomized spherical copper $(\mathrm{Cu})$ metal powder from Alfa Aesar was utilized with a mesh size 100 , equal to a maximum particle size of $149 \mu \mathrm{m}$ (see Figure 3a). Copper compacts with different green densities were prepared using a uniaxial mechanical press. The prepared compacts were cylindrical in shape with an average diameter of $6.4 \mathrm{~mm}$ to exactly fit into the sample holder of the dilatometer system. The length was in the range from 8 to $11 \mathrm{~mm}$.
The as-received copper powder and the microwave sintered Copper samples were characterized using X-ray diffraction (XRD), optical microscopy and scanning electron microscopy (SEM).

\section{Results and Discussion}

Systematic investigation on the sintering behavior with respect to process parameters and sintering atmosphere were performed [4]. The heating process was controlled along a preset temperature-time program using the temperature signal of an S-type sheath thermocouple, touching the sample surface.

Fig. 1 shows the in-situ resistance and dilatometry measurements of copper powder compacts with green densities of about $76 \%$ th.D., sintered at $1000^{\circ} \mathrm{C}$ with 10 min. soaking time using the 3 different process gases. A significant expansion behavior was observed in all the $\mathrm{Cu}$ compacts processed using the hydrogen containing gas $\left(\mathrm{N}_{2} / \mathrm{H}_{2}\right)$. This abnormal expansion behavior was not observed when using the other two gases $\left(\mathrm{N}_{2} \& A r\right)$. Furthermore, a sharp decrease in the electrical resistivity of the $\mathrm{Cu}$ compacts was observed at around $\sim 190-210^{\circ} \mathrm{C}$ when using forming gas, while a gradual steady decrease on the electrical resistivity of similar samples occurred when using the other gases, reaching its minimum at around $600^{\circ} \mathrm{C}$.

These different trends in the electrical resistivity could be explained by the difference in the reduction reaction of the thin copper oxide layer on the metal powder surfaces when comparing $\mathrm{H}_{2}$ induced reaction, in case of forming gas and thermal induced reduction, in case of $\mathrm{N}_{2}$ and Ar. Whereas in the first case water vapor is produced, in later case $\mathrm{O}_{2}$ is formed according to the following reaction equations:

$$
\begin{array}{rlrl}
\mathrm{Cu}_{2} \mathrm{O}+\mathrm{H}_{2} & \rightarrow 2 \mathrm{Cu}+\mathrm{H}_{2} \mathrm{O} & 2 \mathrm{Cu}_{2} \mathrm{O} \rightarrow 4 \mathrm{Cu}+\mathrm{O}_{2} \\
\mathrm{CuO}+\mathrm{H}_{2} & \rightarrow \mathrm{Cu}+\mathrm{H}_{2} \mathrm{O} & 2 \mathrm{CuO} \rightarrow 2 \mathrm{Cu}+\mathrm{O}_{2}
\end{array}
$$

With progressing thermal or chemical reduction the electrical resistivity of the sample decreases due to the continuously improving electric contact between the $\mathrm{Cu}$ particles. In case of forming gas, when water vapor is formed and trapped in intra- and intergranular pores of the developing copper microstructure, due to increasing vapor pressure during heating, the sample expands as can be seen in Figure 1. This expansion was significant in the temperature range from $300^{\circ} \mathrm{C}$ to $500^{\circ} \mathrm{C}$ followed by a subsequent sintering stage starting at around $700^{\circ} \mathrm{C}$ that compensates the previous expansion and reaches a final densification comparable to the $\mathrm{N}_{2}$ process. This unique expansion was observed for any green density, process parameter as well as for other grades of $\mathrm{Cu}$ powders. 

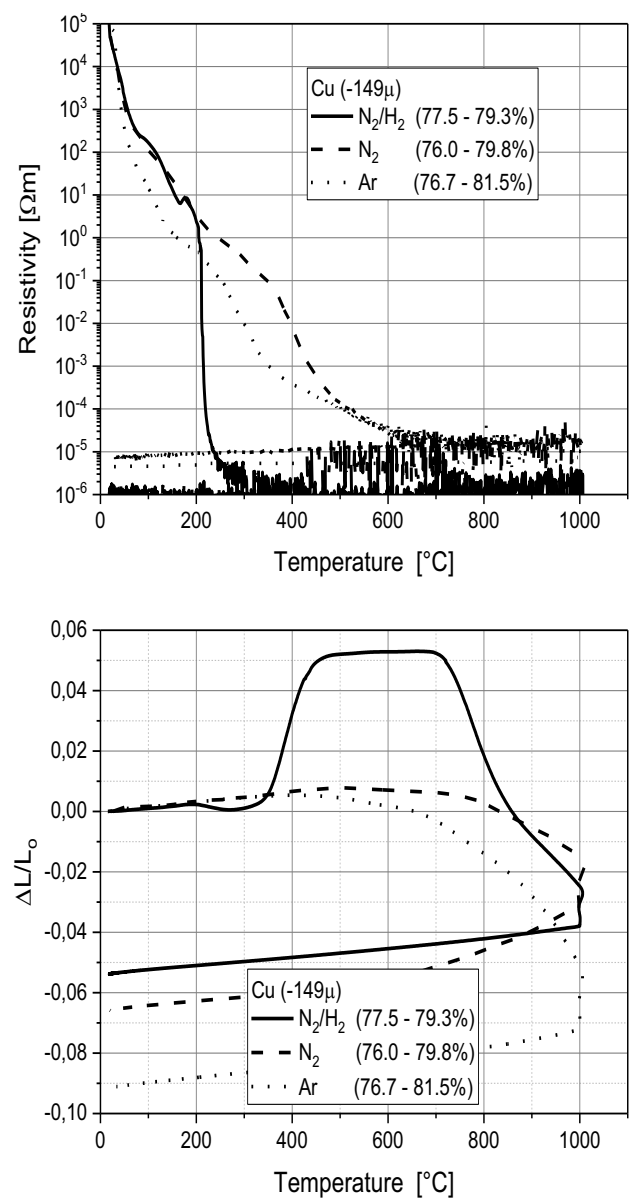

Fig. 1. Resistivity (top) and relative change in length (bottom) of Copper power compacts during sintering at $1000^{\circ} \mathrm{C}$ with 10 min. soak and subsequent free cooling with different process gases. Numbers in brackets reveal relative green and sintered density in $\%$ of theoretical density

This effect can even be identified by comparison of copper powder particles heated at similar conditions for 5 min at $550^{\circ} \mathrm{C}$ (see Fig. 2). Whereas no distortion could be observed for particles processed in $\mathrm{Ar}$ or $\mathrm{N}_{2}$, significant effects are obvious in the forming gas case. The expansion effect is revealed by irregular bursts in particle surfaces, obviously caused by vapor, developing during $\mathrm{H}_{2}$ reduction of $\mathrm{CuO}_{2}$ and captured in closed pores till the pressure reaches the mechanical strength of those.

Comparing the sintering curves in Fig. 1 reveals the best densification behavior in Ar gas. On the other hand, the lowest resistivity could be achieved by using forming gas probably due to most complete reduction reaction. Further parameter studies revealed higher sintered densities with increasing soaking time, and higher green density, as expected. Furthermore more fine grained grades of copper particles allow highest sintered densities and in much shorter times when compared with similar coarsegrained $\mathrm{Cu}$ samples. Finally the $\mathrm{MW}$ processed $\mathrm{Cu}$ samples had achieved higher densities than similar ones processed using conventional heating, as in the $\mathrm{Ar}$ gas case.

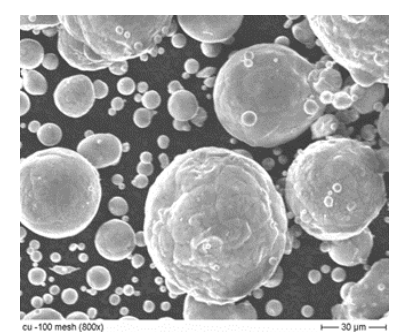

a) As-received $\mathrm{Cu}$ powder

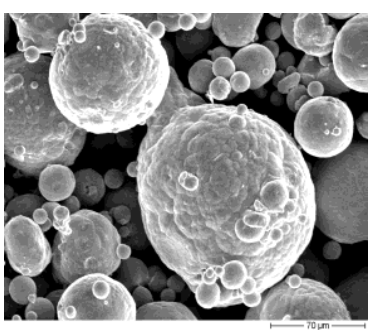

c) $\mathrm{N}_{2}$ gas

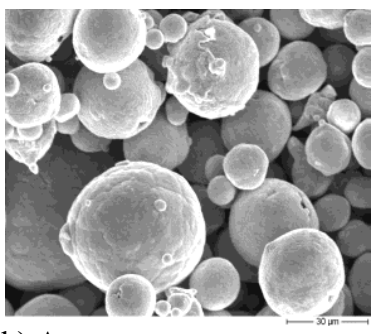

b) Ar gas

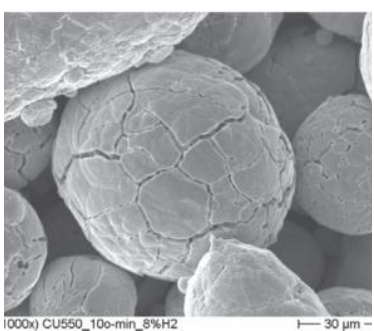

d) forming gas
Fig. 2. SEM of the as-received $\mathrm{Cu}$ powder (maximum particle size $149 \mu \mathrm{m}$ ), compared to $\mathrm{MW}$ treated powder at $550{ }^{\circ} \mathrm{C}$ for $5 \mathrm{~min}$ in different atmospheres

\section{Conclusions}

Systematic experimental studies on mm-wave sintering of copper powder compacts reveal the existence and influence of oxide layers on particle surfaces. Whereas bulk metals hardly allow microwave heating due to limited skin depth, volumetric heating of metal power compacts is possible. Native copper oxide films formed on the particle surface under ambient conditions dominate in the microwave absorption and interaction, the sintering behavior and the microstructural changes.

\section{Acknowledgement}

We acknowledge the support of this project by Deutsche Forschungsgemeinschaft (DFG) under the reference number TH 656/3-1 within the special IndoGerman (DST-DFG) research program.

\section{References}

1. Takayama S., Link G., Miksch S., Sato M., Ichikawa J. \& Thumm M., Millimetre wave effects on sintering behaviour of metal powder compacts // Powder Metallurgy, 2006 V. 49 N. 3 P. 274-280.

2. Rybakov K.I., Semenov V.E., Egorov S.V., Eremeev A.G., Plotnikov I.V., and Bykov Yu.V. Microwave heating of conductive powder materials // Journal of Applied Physics 2006 V. 99,023506

3. Link, G.; Mahmoud, M.M.; Thumm, M., Dilatometric study and in situ resistivity measurements during millimeter wave sintering of metal power compacts // Processing and Properties of Advanced Ceramics and Composites IV. John Wiley \& Sons, New Jersey. 2012. P. 145-149.

4. Mahmoud, M.M., G. Link, and M. Thumm, The role of the native oxide shell on the microwave sintering of copper metal powder compacts. // Journal of Alloys and Compounds, 2015. V. 627 P. 231-237. 